\title{
COMMUNICATIONS
}

\section{OPHTHALMIC MANIFESTATIONS OF BILATERAL NON-OCCIPITAL CEREBRAL LESIONS*}

\author{
BY \\ DAVID G. COGAN \\ Howe Laboratory of Ophthalmology, Harvard University Medical School, \\ Massachusetts Eye and Ear Infirmary, Boston, Mass.
}

To give the Montgomery Lecture is a great honour for any American but perhaps most especially appreciated by one from Boston. It was in this first port of call for the transatlantic ship lines that so many waves of your countrymen disembarked, and took prominent places in the development of that country of opportunity across the seas. We have much in common.

To give the Montgomery Lecture is also a most humbling experience. When I look over the distinguished names of those who have preceded me on this platform I can only wonder at my good fortune in being included among those who have been challenged to uphold the traditions that surround this Lectureship. After recovering from the pleasant surprise of being invited, my first effort was to acquaint myself with the conditions of the lectureship. To this end I secured Dr. Somerville-Large's exquisite vignette, itself the 42nd Montgomery Lecture (Somerville-Large, 1960). I was delighted to read that the lecture was given by young investigators-although I was a little let dqwn when Dr. Somerville-Large subsequently added that this was in the earlierr years of the lectureship. I noted with some sympathy that the Dean of the Medical School was in the habit of coercing students to attend the Lecture so that the hall would appear full.

But I was most impressed by the fact that the second lecture, or series of lectures, was given by Gordon Holmes (1919) on a subject which has preoccupied me of late, namely, some of the specific visual defects of cerebral lesions. In his lecture 45 years ago Holmes concluded that bilateral parietal lesions caused characteristic impairment of visual recognition and localization in space. I hope to deal similarly with some of the visual symptoms resulting from bilateral lesions affecting the visual associative and ocular motor areas.

The present study is, in a sense, a sequel to that based on unilateral lesions in the parietotemporal region and previously reported (Cogan, 1960). I then pointed out, corroborating the many reports of others, that left parietotemporal lesions impaired recognition of visual symbols (alexia and agraphia) whereas right parietotemporal lesions impaired especially judgment of spatial relationships (topographic agnosia and constructional apraxia). Except for diminished optokinetic responses on

* Montgomery Lecture, presented before the Irish Ophthalmological Society, October 8, 1964. 
rotation of the field toward the side of the lesion and for contraversive deviation of the eyes with closure of the lids, ocular motor signs were minimal or absent.

One might expect bilateral lesions in the parietotemporal areas to disturb not only recognition of visual symbols and spatial orientations but also to manifest new symptoms resulting from impairment of functions that are normally represented on both sides of the brain and therefore not evident with unilateral lesions. As Critchley (1953) observes in that most comprehensive text on the subject of the parietal lobes, "bilateral disorders of vision may entail more than a mere arithmetical doubling of the effects of a unilateral lesion".

Previous reports of the visual and ocular motor symptoms of bilateral cerebral disease have been widely scattered in the neurological and neurosurgical literature. Bibliographies may be found in the texts of Critchley (1953), Walsh (1957), and Duke-Elder (1949). References will be given in the present paper only to specific points of interest.

In general, the most relevant symptoms are:

(1) Visual object agnosia (Brain, 1941), whereby patients fail to identify objects that they see and would customarily recognize;

(2) Defective localization of objects in space (Holmes, 1919) with resultant misplaced grasping of objects (Kleist, 1922);

(3) Various disturbances of conjugate gaze.

No author has had any large series of cases and little is known, despite abundant speculation, of the topographical basis for the symptoms.

\section{Present Investigations}

The present series consists of twelve patients (Table) divided arbitrarily into two groups, in whom the symptoms predominantly involved the visual system (Group I) and the ocular motor system (Group II). The second group could be further divided into those in whom the ocular motor defect was an apraxia of gaze (Group IIa) or a prolonged paralysis of gaze (Group IIb).

Group I. Visual Symptoms.-Since Freud (1891) first proposed it, the term visual agnosia has been used to designate failure to recognize an object visually despite intact perceptive mechanisms and adequate mentation. Of the many subtypes (alexia, pictorial agnosia, colour agnosia, etc.) we will be concerned chiefly with those severe forms in which the patient is unable to recognize elementary objects by vision, a symptom generally categorized as visual object agnosia.

Case 1, a 57-year-old auto-mechanic whose initial complaint was "blurring of vision". This was noted first while he was driving his automobile and progressed over a period of several months to the point of bumping into objects. Members of his family observed that he would habitually drive his car on the wrong side of the road and he volunteered that on-coming buses looked half their proper size.

Other complaints early in the course of his disease were bifrontal headaches and unsteadiness of gait. He then developed difficulty in dressing and feeding himself; he confused the right and left sides; and his family and friends appeared strange and unfamiliar to him. He further complained of progressive difficulty in performing tasks with his hands because he would "overshoot" the mark. 
TABLE

\section{CLINICAL FINDINGS IN TWELVE CASES}

\begin{tabular}{|c|c|c|c|c|c|c|c|}
\hline \multirow{2}{*}{ Group } & \multirow{2}{*}{$\begin{array}{l}\text { Case } \\
\text { No. }\end{array}$} & \multirow{2}{*}{$\begin{array}{c}\text { Age } \\
\text { (yrs.) }\end{array}$} & \multirow{2}{*}{ Sex } & \multicolumn{2}{|c|}{ Lesion } & \multicolumn{2}{|c|}{ Chief Signs and Symptoms } \\
\hline & & & & Cause & $\begin{array}{l}\text { Presumed } \\
\text { Site }\end{array}$ & Neuro-ophthalmic & Neurological \\
\hline \multirow{3}{*}{ I } & 1 & 57 & $\mathbf{M}$ & $\begin{array}{l}\text { Metastatic } \\
\text { carcinoma }\end{array}$ & Biparietal & $\begin{array}{l}\text { "Blurring of vision"; alexia and } \\
\text { pictorial agnosia; topographic } \\
\text { agnosia with misplaced grasping; } \\
\text { constructional apraxia; bumping } \\
\text { into objects; left homonymous } \\
\text { hemianopia; questionable ocular } \\
\text { motor apraxia }\end{array}$ & $\begin{array}{l}\text { Right-left confusion; } \\
\text { ankle clonus; seizures; } \\
\text { dressing apraxia }\end{array}$ \\
\hline & 2 & 47 & $\mathbf{F}$ & $\begin{array}{l}\text { Trauma of } \\
\text { implanted } \\
\text { electrodes. } \\
\text { Psychomotor } \\
\text { siezures }\end{array}$ & Bitemporal & $\begin{array}{l}\text { Alexia; pictorial and object } \\
\text { agnosia; right hemianopia }\end{array}$ & None \\
\hline & 3 & 31 & $\mathbf{F}$ & $\begin{array}{l}\text { Congenital } \\
\text { encephalopathy } \\
\text { associated with } \\
\text { prematurity }\end{array}$ & $\begin{array}{l}\text { Diffuse } \\
\text { fronto- } \\
\text { parieto- } \\
\text { temporal }\end{array}$ & $\begin{array}{l}\text { Alexia; object agnosia and prosop- } \\
\text { agnosia; topographic agnosia } \\
\text { with misplaced grasping; probable } \\
\text { bilateral field defects }(\mathbf{R}>\mathrm{L}) ; \\
\text { delayed pursuit movements; } \\
\text { apraxia of ocular movements and } \\
\text { lid opening }\end{array}$ & $\begin{array}{l}\text { Scissors gait; bilateral } \\
\text { facial weakness; hyper- } \\
\text { reflexia of all extremities }\end{array}$ \\
\hline \multirow{5}{*}{ IIa } & 4 & 27 & $\mathbf{M}$ & $\begin{array}{l}\text { Thrombosis of } \\
\text { sagittal sinus }\end{array}$ & Biparietal & $\begin{array}{l}\text { Ocular motor apraxia; anomalous } \\
\text { fixation of gaze }\end{array}$ & $\begin{array}{l}\text { General negativism or } \\
\text { akinetic mutism; apraxia } \\
\text { of leg; hyper-reflexia; } \\
\text { bilateral ankle clonus; } \\
\text { extensor plantar reflexes }\end{array}$ \\
\hline & 5 & 60 & $\mathbf{F}$ & Meningitis & $\begin{array}{c}\text { Bilateral } \\
\text { fronto- } \\
\text { parietal }\end{array}$ & $\begin{array}{l}\text { Ocular motor apraxia; partial left } \\
\text { homonymous hemianopia }\end{array}$ & $\begin{array}{l}\text { Right hemiparesis and } \\
\text { hemianaesthesia; akinetic } \\
\text { mutism }\end{array}$ \\
\hline & 6 & 44 & $\mathbf{F}$ & $\begin{array}{l}\text { Metastatic } \\
\text { carcinoma }\end{array}$ & Biparietal & $\begin{array}{l}\text { Ocular motor apraxia; } \\
\text { papilloedema and 6th nerve } \\
\text { paralysis }\end{array}$ & $\begin{array}{l}\text { Apraxia of right side; } \\
\text { unawareness of right side } \\
\text { of body; right hemipare- } \\
\text { sis and hemihypaesthesia }\end{array}$ \\
\hline & 7 & 43 & $\mathbf{F}$ & Motor accident & $\begin{array}{c}\text { Bilateral } \\
\text { fronto- } \\
\text { parietal }\end{array}$ & $\begin{array}{l}\text { Ocular motor apraxia; fixation of } \\
\text { gaze; 3rd nerve paralysis; inter- } \\
\text { dependence of head and eye } \\
\text { movements }\end{array}$ & $\begin{array}{l}\text { Right hemiparesis; } \\
\text { bilateral extensor plantar } \\
\text { reflexes; akinetic mutism }\end{array}$ \\
\hline & 8 & 48 & $\mathbf{F}$ & $\begin{array}{l}\text { Inclusion body } \\
\text { encephalopathy }\end{array}$ & Bitemporal & $\begin{array}{l}\text { Partial object agnosia; blepharo- } \\
\text { spasm; ocular motor apraxia }\end{array}$ & $\begin{array}{l}\text { Akinetic mutism; con- } \\
\text { fused body parts and } \\
\text { laterality }\end{array}$ \\
\hline \multirow{4}{*}{ IIb } & 9 & 55 & $\mathbf{F}$ & $\begin{array}{l}\text { Cerebrovascular } \\
\text { accident }\end{array}$ & $\begin{array}{c}\text { Bifronto- } \\
\text { parietal }\end{array}$ & $\begin{array}{l}\text { Paralysis of gaze to left; left } \\
\text { hemianopia }\end{array}$ & $\begin{array}{l}\text { Previous right hemiplegia; } \\
\text { expressive aphasia }\end{array}$ \\
\hline & 10 & 60 & $\mathbf{F}$ & $\begin{array}{l}\text { Cerebrovascular } \\
\text { accident }\end{array}$ & Bifrontal & $\begin{array}{l}\text { Paralysis of gaze to right; } \\
\text { weakness of gaze to left }\end{array}$ & $\begin{array}{l}\text { Previous left hemiparesis; } \\
\text { present right hemiplegia; } \\
\text { expressive aphasia }\end{array}$ \\
\hline & 11 & 46 & $\mathbf{F}$ & $\begin{array}{l}\text { Occlusion of } \\
\text { cartoid arteries }\end{array}$ & Bifrontal & Paralysis of gaze to left & $\begin{array}{l}\text { Previous right hemiplegia; } \\
\text { present left hemiplegia } \\
\text { and hemianaesthesia }\end{array}$ \\
\hline & 12 & 28 & $\mathbf{F}$ & Unknown & $\begin{array}{l}\text { Fronto- } \\
\text { parietal }\end{array}$ & $\begin{array}{l}\text { Paralysis of gaze to left and up; } \\
\text { paralysis of convergence; poor } \\
\text { fixation }\end{array}$ & $\begin{array}{l}\text { Previous "nervous break- } \\
\text { down"; present left } \\
\text { hemiplegia and hypaes- } \\
\text { thesia; bilateral ankle } \\
\text { clonus and extensor } \\
\text { plantar reflexes }\end{array}$ \\
\hline
\end{tabular}

On the initial examination the patient was alert and accurately oriented in time and place. $\mathrm{He}$ recognized objects properly and could recite a series of numbers correctly. He was, however, unable to draw the simple diagram of a house or a clock-face. Although he was able to write out a sequence of numbers from 1 to 12 he was unable to insert them in a circle corresponding to their positions in a clock-face. He could identify the fingers on his own hands or on those of the examiner but he confused the right and left sides.

He had a complete left homonymous hemianopia and increased tone in the left arm. Stereognosis and vibration sense were present and equal bilaterally.

A right parietal craniotomy was performed (by Dr. H. T. Ballantine) with excision of two 
metastatic nodules near the surface. Pathologically they appeared to be of thyroid origin and subsequent investigation revealed palpable nodules of the thyroid which were interpreted as carcinomatous.

One week after the craniotomy the patient developed difficulty in recognizing or naming objects in the right visual field and he was no longer able to do the simple calculations that had been possible pre-operatively. . A few days later he developed clonic seizures of the right arm and a brain scan with $\mathbf{I}^{131}$ localized a lesion in the left parietal area. The motor reflexes were then, and for some time thereafter, bilaterally hyperactive, with bilateral ankle clonus but curiously with flexor plantar responses. The patient identified objects and coins in both hands but was unable to detect the size difference of coins in the right hand as well as he did in the left. He had especial difficulty in putting on stockings or slippers and when asked to get into bed he would frequently lie across the bed or place his head at the foot end without realizing the inconsistency of it. When asked to sit in a chair (Fig. 1) he would approach it, feel the back of it, but often sit beside it and land on the floor. He appeared not to know where the chair was although he could see it sufficiently well to approach it on command even when it was some distance away.

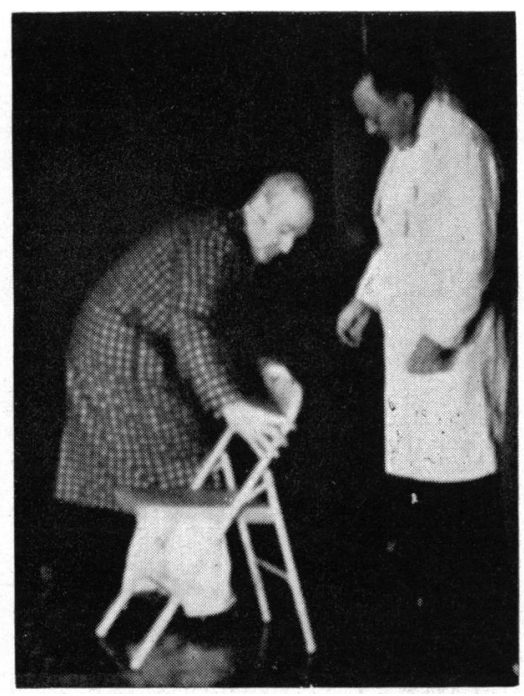

Fig. 1.-Case 1. When asked to sit in a chair, the patient approached it hesitatingly, felt it with his hands, and often seated himself beside it. [Reproduced from moving-picture film.]

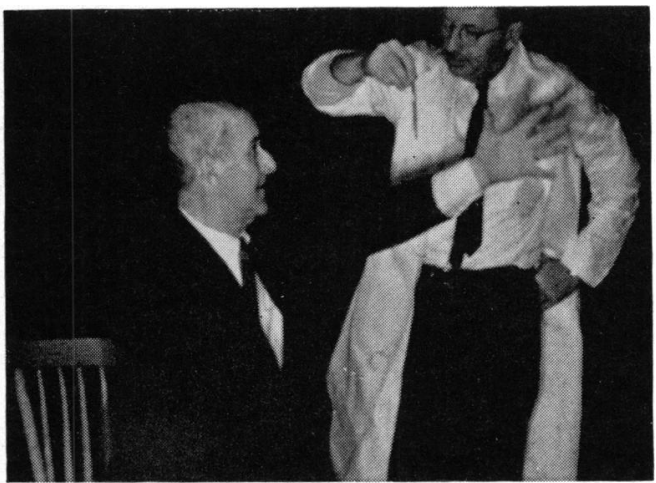

FIG. 2.-Case 1. When asked to touch the pencil, he would usually reach beyond it, although other evidence indicated that he could see it adequately. [Reproduced from moving-picture film.]

The patient was alert and cooperative and looked directly at objects most of the time when instructed to do so but he was unable to maintain fixation. When asked to touch objects in his visual field he regularly reached below or beyond them (Fig. 2) and frequently accused the examiner of removing them as he reached for them. With his eyes closed, however, he accurately located voices. He bumped into objects, walls, and persons that he nevertheless saw. He was able to approximate the index fingers of his outstretched hands with a fair degree of accuracy.

He had difficulty in identifying letters and no accurate measurement was made of visual acuity. $\mathrm{He}$ did recognize the large $\mathrm{E}$ at 20 feet $(20 / 200)$ but was unable to tell in which direction the arms of the letter pointed. He was unable to identify words or pictures in a magazine and was often unable to tell whether the pages were right side up or upside down. He did recognize colours accurately, however.

The eye movements were full both on command or on following an object and were not associated with nystagmus. Yet he could not be relied upon to make the correct movement more than 50 per cent. of the time. Whether this failure to respond was apractic or aphasic could not be ascertained. The optokinetic response was not elicitable either horizontally or vertically. The 
fundi were not remarkable. The visual fields were difficult to plot accurately because of the poor fixation, but a left homonymous hemianopia was present and most dense (absolute to hand movements) in the inferior quadrants.

Several examinations over the subsequent few weeks confirmed the foregoing with the findings of: (1) striking inability to localize objects visualized in space but relatively accurate localization of auditory stimuli; (2) bumping into objects to an incapacitating degree; and (3) inability to identify letters or pictures but good preservation of colour perception.

About one month after the craniotomy the patient developed seizures involving particularly the right arm and abdomen, progressive aphasia, an abdominal mass, and a fever. He died 9 weeks after the craniotomy. No autopsy was permitted.

Comment.-This is the record of a patient whose cerebral symptoms were at first those of topographic agnosia and hemianopia due to a right parietal lobe lesion but rapidly progressed to visual agnosia and other signs pointing to a left parietal lesion as well. The unusual symptom not seen with unilateral lesions and not explained by any perceptive inability was the profound abnormality of spatial judgment. He showed gross inability to localize objects reached for and faulty judgment of the position of objects in reference to himself. This was incapacitating to the extent that he was unable to seat himself in a chair, to orientate himself in bed, or to avoid objects in his immediate vicinity. In striking contrast to this stereoscopic defect, he was able to recognize colours well, to "see" the 20/200 figure, and to localize objects in space with a fair degree of accuracy by auditory stimuli. His ability to approximate the fingers of his outstretched hands indicated no executive apraxia.

The surprising preservation of colour perception despite the profound visual agnosia has been a feature of other cases (Brain, 1941; Nielsen and Sanborn, 1942). The misdirected grasping for objects which the patient showed for visual but not for auditory stimuli is what Kleist (1922) called "optical ataxia". The inability to localize objects in space was described by Holmes (1919) and by Faust (1947) after bilateral parieto-occipital lesions.

Case 2, a 47-year-old housewife, was first seen at the Massachusetts General Hospital with a history of psychomotor seizures for 10 years. These were characterized by momentary loss of contact with the environment, occasionally accompanied by falls to the floor, and followed by mild confusion. The seizures had recently increased in frequency to as many as four per day and one attack had resulted in her being struck by a car. The attacks were poorly controlled by medication.

Since neither the neurological examination nor the electro-encephalogram revealed any focal abnormality and since the seizures had become incapacitating, stereotactic electrodes were implanted in both temporal lobes (by Dr. W. Sweet). Before this surgery, ophthalmological examination, including that of the visual fields, was entirely normal. Psychological testing also showed normal visual and auditory functions including word associations, colour perception, and interpretation of written commands.

For insertion of the electrodes four occipital burr holes were made, two on each side. Pantopaque was injected into the lateral ventricles and under $x$-ray visualization an electrode was placed in each of the four burr holes and locked in situ. One pair of the electrodes was passed through the occiput $2.7 \mathrm{~cm}$. to either side of the midline to reach the amygdaloid nuclei. The other two were advanced to the anterior part of the temporal lobe.

The day following surgery the patient complained of tinnitus and "blackouts". On examination she was found to have a severe and highly selective visual agnosia. She could not read simple words or statements although she was alert and replied appropriately to auditory commands. Some observers thought she was blind while some others thought she was hysterical.

When, 5 days later, her general condition permitted an intensive neuro-ophthalmic examination, she was found to have a partial right homonymous hemianopia. She was unable to read any letters on the Snellen chart but by copying and by her own testimony she could identify figures of the 20/30 
line. She was unable to identify numbers or even to ascertain whether or not they were upside down. Pictures and simple diagrams were meaningless to her and could not be orientated properly. She was unable to identify common objects by visual clues, not even the door in her room, nor could she recognize visually the doctors and nurses who attended her. Colours were also meaningless to her.

Yet she was remarkably alert and compensated for her profound visual inadequacy by subtle auditory and tactile clues. Thus when she was asked to tell which was the door and which the window in her room she hesitated a moment and then correctly identified the door because she "could hear nurses' voices in the corridor" through it. She similarly learned quickly to recognize attendants by their voices. When asked the colour of her toothbrush she was at a loss until she felt it and then correctly identified it as red because "that is the colour of my toothbrush". She was able to write easily on dictation but later was unable to read what she had written. She had excellent verbal spelling and did serial numbers. There was no right-left confusion and no finger agnosia. The ocular movements including the optokinetic responses were entirely normal.

During the subsequent 2 weeks the patient recovered her ability to identify some letters of the alphabet and some words but she continued to have difficulty identifying abstract pictures, threedimensional diagrams, and colours in the isochromatic chart. The right hemianopia persisted but was less dense.

Several electrocautery lesions were made and the electrodes were removed 7 weeks after their insertion. By this time the patient had regained her ability to recognize objects and to read and her visual fields were full. Following removal of her electrodes, however, she again had transient dyslexia and loss of ability to do crossword puzzles.

Comment.-This patient, who had had psychomotor epilepsy but normal visual functions, developed a profound and highly selective visual agnosia following placement of stereotactic electrodes in both temporal lobes. The agnosia was characterized by loss of ability to recognize letters, words, objects, faces, and colours. Although accompanied by a partial right hemianopia, the agnosia was much more profound than is the usual alexia of left parietal disease.

Also noteworthy in this patient were the normal ocular motor functions and the intact auditory and tactile modalities of sensation by which the patient compensated for her loss of visual interpretive functions.

Case 3, a 31-year-old woman whose relevant history dated from birth, was said to have been born 4 months prematurely and to have weighed only $2 \mathrm{lb}$. at birth. She walked at $2 \frac{1}{2}$ years of age but was always clumsy. She could never learn to run, skate, skip, or knit. She described having had an "inflexible tongue" and having been given speech therapy as a child.

In school the patient kept up with her classmates, graduating from high school and college at the normal age with a creditable record. Yet she had never been able to take notes or write legibly. For notes she relied on her classmates and for examinations she was either given oral tests or was allowed several times the normal period for other students. She had the reputation of having a phenomenal memory and by her testimony she had adopted many artifices "to fool people into thinking she was normal".

She comprehended speech readily but had to labour over printed material. Even individual letters were read with difficulty and many errors. To recognize names on buses she had the names classified according to their lengths; she picked the right bus by the length of the word rather than by its spelling.

So well did she compensate for her inability to recognize visual symbols that the extent of her agnosia became manifest only after a relatively prolonged interview. Thus it was not apparent in our first contact with the patient that she could distinguish the two examiners only by the sounds of their voices. She, of course, was aware of this and related that, when serving as a substitute teacher for a grade school, she had been able to distinguish her students only by the sounds of their voices. She told the amusing but informative story of having been unable to distinguish her escort at a dance from several other boys because he and they were so quiet. Other gross defects in the patient's visual recognition will be described subsequently. 
Disorientation in space had also been one of the patient's major handicaps. To get from one place to another, even so simple a trip as down the corridor and around a corner, the patient would count her steps and make a mental note of the angle of any turns so that she would be able to return. On the street automobiles would be sensed as to their position and direction of movement by the sounds they made. When in a strange place, the patient would habitually make a mental note of the position of people and articles by sound and touch. If she had an important appointment at a designated place she would make a trial run the day before, picking out notable landmarks along the way and measuring distances.

Despite these gross impediments in visual function, the patient was highly intelligent when tested by auditory means and was completing requirements for a Ph.D. degree in "speech and hearing therapy"!

Ophthalmic examination revealed a visual acuity of 20/30 in the left eye (letters identified with difficulty) and an amblyopia and esotropia of the right eye with a visual acuity of hand movements. The pupils reacted promptly and the fundi were normal except for possible mild pallor of the nerve heads.

The eyes moved purposively on command but only after a delay of several seconds and then with a preferential movement of the head (Fig. 3). The pursuit movements were similarly delayed and often executed with saccadic jerks. Horizontal and vertical movements were affected equally. On fixing an object the patient held it with a Parkinsonoid stare and infrequent blinking. There were, however, occasional flutter-like closures of her lids and after she forcibly closed her eyes she was unable to open them for a few seconds. The optokinetic responses were normal and the eyes neither showed lateral deviation with closure of the lids nor maintained deviation with rotation of the body.

The visual fields were difficult to assess because of the patient's slow responsiveness, but she seemed to have bilateral defects that were greater in the right homonymous fields.

Neurological examination (by Dr. Miller Fisher) disclosed a moderate scissors gait, bilateral facial weakness, mild rigidity of arms and legs, hyper-reflexia of all four extremities (although plantar responses were flexor) and gross clumsiness of the hands. Vibration sense was, however, everywhere intact, motor power in the limbs was good, and there was no cerebellar ataxia.

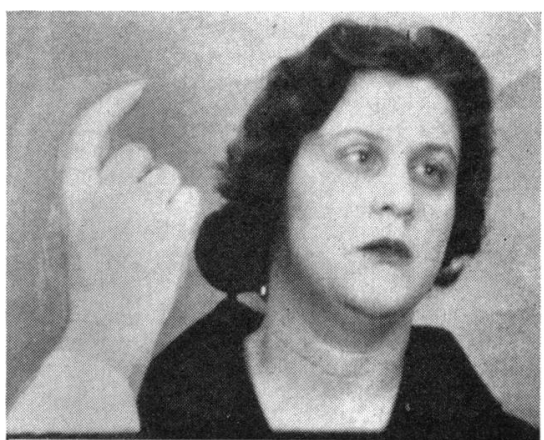

Fig. 3.-Case 3. When asked to look to one side she would hesitate for 1 or 2 seconds and then move her head instead of her eyes. [Reproduced from movingpicture film.] Theneurological impression was that of cerebral diplegia.

In several interviews with the patient confirmatory and additional observations were made. One remarkable symptom was gross loss of visual position sense. The patient regularly overshot or undershot objects reached for. When asked to note the position of an object in space and then, with eyes closed, to point at it, she frequently missed the mark by a wide margin. She had adopted several tricks for localizing objects. Thus, on one typical occasion, while sitting in a chair she was observed to put her handbag on the floor adjacent to her left leg. When asked to pick up her bag she slid her hand down her leg until level with her ankle, then moved her hand over the handle of the bag. She did not look at the bag during this act. The subsequent dialogue ran as follows:

"Could you see your handbag?"

"Yes."

"Why didn't you look at it directly, then, and pick it up?"

"Because if I had looked at it I would have either overshot the mark or grasped it at some place other than its handle."

The patient was obviously using her sense of touch for localization in preference to vision. She had developed subtle means of identifying objects shown her and much reliance was placed on size. She recognized a pencil and identified its colour promptly, but when asked to identify a folding match carton she said: 
"You took it out of your pocket and it is too small for cigarettes; it must be matches."

A ring was recognized with some hesitancy as a shiny metal that had the appropriate size for a ring. On leaving the examination room the patient approached the elevator properly but then ran her hand over the wall like a blind person to find the buttons.

Comment.-This patient with bilateral cerebral lesions dating from birth had a profound visual agnosia for people, words, and letters, and an ocular motor deficiency that probably represented an apraxia of gaze. Visual projection of objects in space was also grossly deficient. Yet auditory and tactile clues together with native intelligence so effectively compensated for the visual defect that casual observers were unaware of the extent of the agnosia, and the patient was progressing, although somewhat laboriously, through the ranks of higher education!

A somewhat similar case of visual object agnosia was reported by Brain (1941) in a boy with unlocalized brain damage resulting from septicaemia at the age of 7 years. The patient was unconscious for a period of 2 weeks and was thereafter unable to identify simple objects such as a penknife unless he could handle them. He recognized his mother only by her voice. He recognized colours well but could not match pictures with objects and could make only elementary drawings. He had great difficulty in finding his way about; to reach the nearby shops he had memorized certain aids, such as the distance travelled, the trees, and the turns in the road. The author's chief interest in reporting the case was the relevance of the patient's symptoms to the Gestalt theory and he gave no adequate account of the neurological findings or presumed localization of the lesion.

Group II. OCUlar Motor Symptoms.-In this group ocular motor manifestations predominated; if visual interpretive functions were abnormal, they were inconspicuous or overlooked.

(a) Ocular Motor Apraxia.-The first patient of this group has been previously reported as illustrative of ocular motor apraxia (Cogan and Adams, 1953), which is also called Balint's syndrome (Cogan and Adams, 1955).

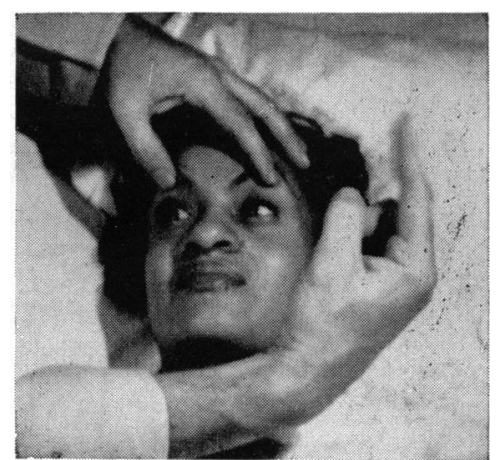

FIg. 4.-Case 4. She was unable to relinquish fixation on the examiner when asked to look at fingers on her left side. [Reproduced from movingpicture film.]
Case 4, a 27-year-old woman, developed fever ( $101^{\circ} \mathrm{F}$.), a raised white blood cell count, and a series of convulsions on the fifth post-partum day. For the next 2 weeks she lay in the bed showing slow responsiveness, purposeless movements of the legs, and a lack of fixation of the eyes. She gave the impression of negativism and her condition was at first interpreted as hysteria or catatonic schizophrenia. As she recovered, however, it became apparent that her anomalous behaviour represented an apraxia and that her inability to move her eyes voluntarily was part of the general syndrome. This ocular abnormality was characterized by inability to change her gaze from one object to another on command despite full random movements when not pressed. She would fix an object or person brought into her line of sight but would not change this even when addressed by another person (Fig. 4). This gave rise to the curious circumstance that she would hold fixation on one person when answering to the questions of another 
person. When commanded to look at an object she would frequently show no movement or (like a patient reported by Walsh, 1957) would even look in the wrong direction. This was especially true when she was asked to look to the left (Fig. $5 a, b, c$ ). The optokinetic responses were present but diminished bilaterally. She recognized colours adequately. The visual fields were full and the visual acuity was normal.

Neurological examination showed, apart from the apraxia of the limbs, bilateral extensor plantar reflexes, general hyper-reflexia, bilateral ankle clonus, and electro-encephalographic evidence of bifrontal lobe lesions. The patient gradually recovered and after 3 months was considered to be normal.

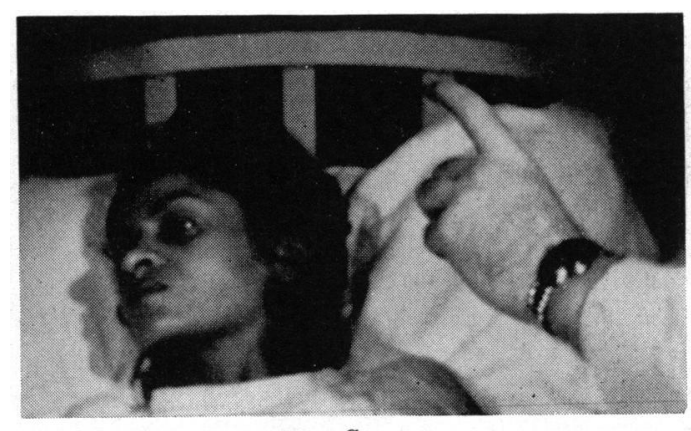

$a$

Fig. 5.-Case 4. When asked to look at the outstretched finger on her left side $(a)$, she made a false movement of her head to the right $(b)$ and was able to turn it to the left $(c)$ only after a hesitation of several seconds. It was during one of these misdirected moves that the patient volunteered that she could turn to the left better if the examiner would stop urging her. [Reproduced from moving-picture film.]
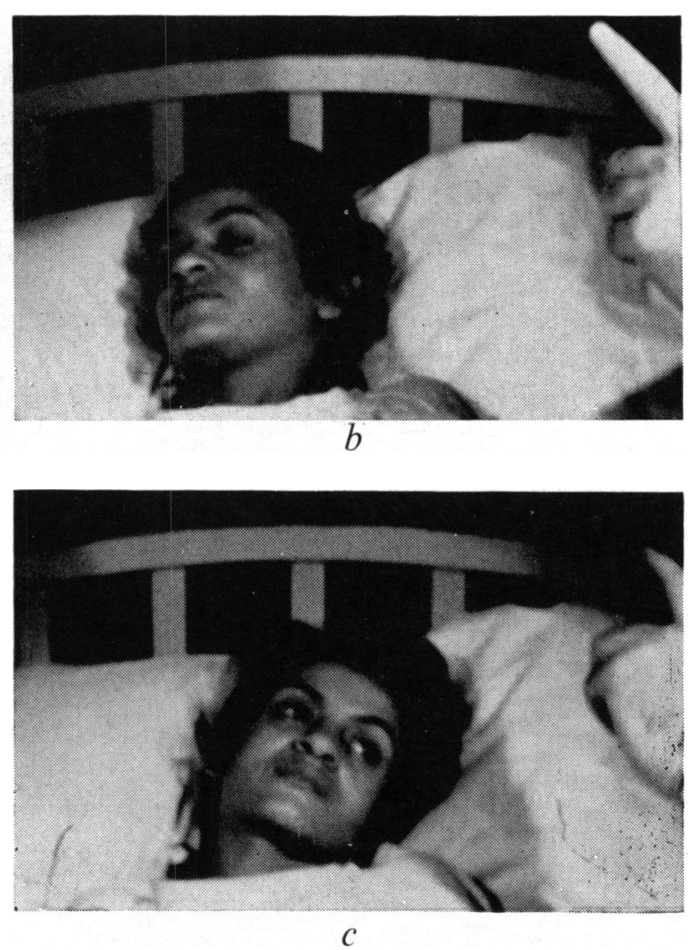

Comment.-This patient with symptoms of post-partum thrombosis of the sagittal sinus developed an apraxia of the limbs and eye movements. Other symptoms were a pathological retardation of responsiveness (akinetic mutism), anomalous fixations of gaze, and an apparent negativism. So far as could be tested, the visual functions, aside from the ocular motor defect, were normal.

Case 5, a 60-year-old woman, developed bacterial meningitis with chills, fever, headache, and stiff neck, a few days after treatment of a dental infection. The cerebrospinal fluid yielded 7,000 w.b.c./ $\mathrm{mm} .^{3}$ and Gram-positive cocci on smear. The fluid was not cultured but a mouth culture grew alpha haemolytic Streptococcus viridans. Blood cultures were negative.

The patient developed left hemiparesis, progressive stupor, and eventual coma. With intensive antibiotic therapy she regained consciousness and at first had decerebrate rigidity. With improvement she also showed right-sided motor weakness, right-sided hypaesthesia, and an akinetic mutism, whereby she appeared alert to what was going on but responded merely by a nod or gesture and an occasional word or two.

She would occasionally move her eyes fully to either side without appreciable nystagmus or dissociation, but she would do so on command only reluctantly. This was at first thought to be merely due to a negativism on the part of the patient, but its apractic nature became evident on partial recovery when she was much more reluctant to look to the left than to the right. She would 
turn her eyes to the left only after a period of several seconds and would then let them drift back to the right. Similarly she would look up above the horizontal line to only a slight degree but would look down relatively well. The optokinetic response was present on movement of the field to the patient's left but absent to the right. Because of the patient's mutism the visual fields could not be plotted but cooperation was sufficient to indicate a partial left homonymous hemianopia.

During the subsequent weeks the patient became more communicative and mentally competent. Examination of the eyes 7 months after the onset showed normal movements and symmetrical optokinetic responses.

Comment.-After an attack of meningitis with bilateral cerebral signs, the patient developed mutism and a reluctance or inability to move her eyes upwards or horizontally. The horizontal inhibition was more marked to the left and was accompanied by a left homonymous hemianopia.

Although this patient (like Case 4) gave the initial impression of a negativistic refusal to move her eyes, the later asymmetry and associated field and optokinetic tests indicated an underlying organic disturbance.

Case 6, a 44-year-old woman, had developed headaches, vomiting, transient motor aphasia, and convulsions 12 months before the present examination. She gave a history of having had a radical mastectomy 2 years previously for carcinoma.

Examination disclosed decreased optokinetic responses bilaterally, papilloedema, and a 6th nerve paralysis, but no other ocular abnormality. Arteriography and ventriculography showed evidence of bilateral parietal tumours. Biopsy of the left parietotemporal area disclosed a metastatic carcinoma.

After craniotomy the patient had a right hemiparesis and remained confused with little spontaneous speech; 2 weeks after the operation she would not, or could not, move her eyes on command adequately, and on being told to look in one direction would often turn her eyes in the opposite direction. She gave the contradictory impression of being blind and yet able to see. The pupils were normally reactive.

She moved the left side of her body properly on command but the right side moved only randomly and she had no awareness of the right side of her body. When pins were stuck in her right side she was aware only of a disagreeable sensation without being able to locate the pins.

She was discharged to a nursing home and not followed further.

Comment.-This patient with metastases in both cerebral hemispheres showed a persistent inability to move her eyes appropriately to either side. Sometimes the eyes turned towards the opposite side to that intended. The general impression was that of blindness. The patient's stupor prevented adequate evaluation of the visual functions, but the ocular motor defect was unlike that occurring with blindness and was interpreted as apraxia. The patient had a similar apraxia of the right leg.

Case 7, a 43-year-old woman, was stuporous or unconscious for several days after a motor accident. On regaining responsiveness she had bilateral extensor plantar reflexes, right hemiparesis, right third nerve paralysis, and akinetic mutism. Although she responded appropriately with a blink of her lids, she made no attempt to speak or move her eyes. The eyes maintained a fixed gaze forward suggesting to some that she was blind. Yet with passive rotation of the head she showed full ocular excursions and a normal nystagmus.

The patient was thought to have bilateral cerebral injury, most marked on the left side, with involvement of the pyramidal tracts and Broca's area. The fixation of gaze was interpreted as a palsy of voluntary conjugate gaze.

Over the ensuing few weeks the patient's mentation gradually improved, she responded to questions, and the eye movements gradually returned. At first, however, she was unable to turn her eyes to the right unless her head was allowed to turn simultaneously.

Comment.-This patient with bilateral brain injury developed temporary akinetic mutism and palsy of voluntary gaze. During recovery the gaze movements returned 
asymmetrically, in accordance with the inequality of the cerebral lesions, and were for a time dependent on coordinate head movements.

Case 8, a 48-year-old woman, had a presumptive diagnosis of inclusion body encephalopathy affecting both temporal lobes.

The initial symptom was the rapid onset of malaise thought to be due to a "cold" from exposure while sailing. The next day she became confused and restless, and developed a right-sided tremor. Her family said she "talked nonsense". Her temperature was $101^{\circ} \mathrm{F}$. and the white blood cell count was 9,400 . $X$ rays of the chest were negative.

On admission to the hospital 4 days after the onset of this condition the patient showed a lack of communication which was thought to represent receptive and expressive dysphasia. She appeared unable to recognize the parts of a watch but could recognize a pen or a shoe. She was unable to spell. She confused body parts and laterality. Her reflexes were somewhat more brisk on the left than the right but were within normal limits and the plantar responses were flexor. The eye movements were full and normal except that blepharospasm was conspicuous and the eyes were kept closed most of the time. Confrontation fields were full but cooperation did not permit the determination of visual acuity. The pupils measured $2.5 \mathrm{~mm}$. and reacted normally. $X$ rays of the chest showed no abnormality. Lumbar puncture revealed normal pressure at $138 \mathrm{~mm}$. of water with lymphocytes 152 and monocytes $8 \mathrm{~mm} .{ }^{3}$, total protein of $65 \mathrm{mg}$. per cent. and sugar $56 \mathrm{mg}$. per cent. Blood sugar was $100 \mathrm{mg}$. per cent.

During the first 2 weeks in the hospital she responded by gestures and then only to simple commands. Nevertheless, the responses were appropriate and the patient seemed alert. She occasionally smiled appropriately but did not speak and showed little spontaneous activity. Some of us felt her symptoms were those of akinetic mutism. She was totally incontinent.

Examination of the eyes showed most conspicuously a reluctance to look to the right. The patient lay in bed with her eyes closed most of the time. Manual attempts to open the eyes resulted in forced blepharospasm and a normal upward deviation of the eyes. On command the patient would keep her eyes open and look at objects on her left side but could only rarely be coaxed to look at objects on her right side. She gave the impression of not making an effort to look to the right and showed none of the drifting characteristic of a patient with a true paralysis. Vertical movements were full on urging although upward gaze was often accompanied by several vertical jerks. There was, however, no true nystagmus and no dissociation of the eyes.

Five weeks after admission to the hospital, during which time she had received only supportive treatment, the patient improved dramatically over a period of several days. She became communicative, her eyes moved with equal facility to either side, and she was essentially normal. When asked what trouble she had had with her eyes during the previous month, she volunteered that she had been unable to look to the right.

Comment.-This patient had an ocular motor apraxia associated with a form of akinetic mutism believed to be due to inclusion body encephalopathy. The signs and symptoms suggested involvement of both temporal lobes.

(b) Paralysis of Conjugate Gaze.-These patients showed a gross paralysis of conjugate gaze which, unlike that due to unilateral lesions, persisted after they recovered consciousness.

Case 9, a 55-year-old woman, had had mild hypertension for a number of years and a cerebrovascular accident 3 years previously. The latter had been characterized by an initial numbness of the right hand progressing to involve the entire right arm and right side of face with eventual rightsided hemiplegia and motor aphasia. No ocular abnormality was noted at that time. The lesion was thought to involve the internal capsule region in the left hemisphere. The patient recovered in the subsequent few weeks so that she was asymptomatic.

The present admission to hospital was prompted by a recurrence of aphasia, a paralysis of conjugate gaze to the left, a left-sided facial paralysis, a partial left hemianopia, and a left extensor plantar response. The new lesion was thought to be deep in the right hemisphere. 
The most conspicuous ocular symptom was a maintained deviation of the eyes to the right. Although alert and cooperative the patient was unable to move her eyes to the left of the primary position (Fig. $6 a, b$ ), nor could she look upward above the horizontal meridian. The optokinetic response was absent on rotation to the right but present on rotation to the left. There was no nystagmus or dissociation of the eyes. The head movements were full.

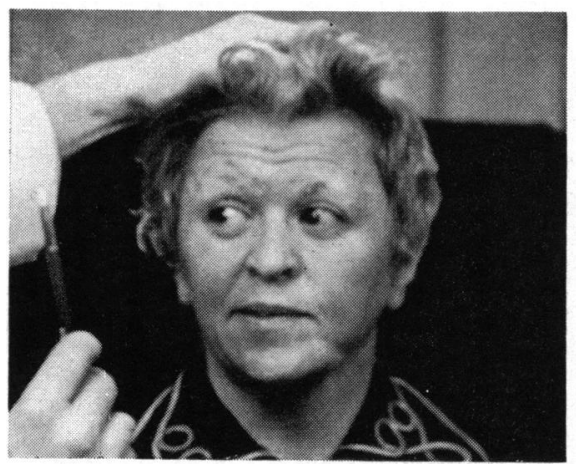

$a$

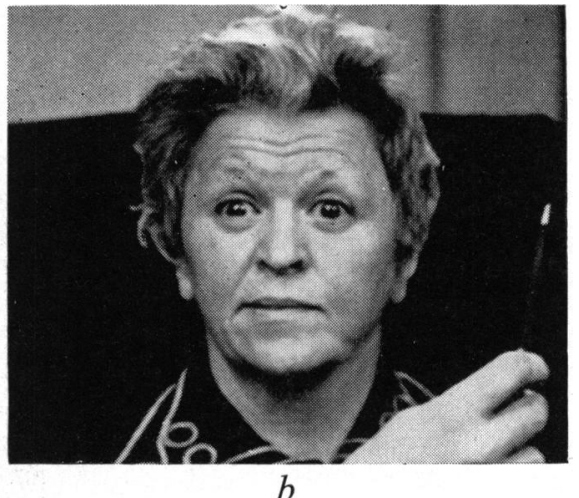

$b$

Fig. 6.-Case 9. She had full excursion of gaze to the right (a) but was unable to look to the left beyond the mid-line $(b)$. [Reproduced from moving-picture film.]

The patient was followed for 2 years. Her aphasia improved but some stuttering persisted. Her ocular movements improved within 2 months, but even 2 years later the gaze to the left was slow and uncertain, while the upward gaze was still nil.

Comment.-This patient had a cerebrovascular lesion in one hemisphere followed 3 years later by a similar lesion in the opposite hemisphere; she developed persistent paralysis of the conjugate gaze after the second lesion. The first episode suggested predominantly a frontal lobe lesion and the second episode a predominantly parietotemporal lobe lesion.

Case 10, a 60-year-old man, had suddenly developed a left hemiparesis $3 \frac{1}{2}$ years previously. The symptoms cleared in a few weeks and were not further documented, but the patient was noted to be hypertensive.

The present episode, which began one week before the examination, was characterized by progressive speech difficulty and right hemiplegia. Neurological examination showed complete motor aphasia, increased deep tendon reflexes, extensor plantar response on the right, and right hemiplegia. The diagnosis was bilateral cerebrovascular accidents.

The eyes showed paralysis of conjugate gaze to the right and weakness of conjugate gaze to the left, but this palsy was curiously variable. Usually the patient would not look to the right more than $15^{\circ}$, but with much urging he could be induced to move the eyes momentarily as much as 25 to $30^{\circ}$. He would readily turn his eyes to the left although never fully. Vertical excursions were normal. When the right ear was irrigated with cold water the eyes maintained dextroversion without nystagmus.

Otherwise the eyes, including the fundi and visual fields, were entirely normal. Ophthalmodynamometry indicated equal and normal arterial pressures in both eyes. The optokinetic responses were not tested.

On a regimen of anticoagulant therapy, the patient improved within a few days. He was not re-examined, however, until 6 months later at which time he still showed mild limitation of conjugate gaze to the right and mild residual right hemiplegia.

Comment.-This patient had bilateral cerebrovascular accidents that were thought to lie in the areas of the middle or anterior cerebral arteries. With the second episode, separated from the first by a period of $3 \frac{1}{2}$ years, the palsy of conjugate gaze persisted. 
Case 11, a 46-year-old woman, first had a sudden onset of biparietal headache, right-sided hemiplegia, and right-sided hemianaesthesia. No abnormality of the eyes was noted with this initial episode but the visual fields were not tested. The symptoms cleared within a few days.

Four months later she developed hemiplegia and hemianaesthesia on the left with left-sided hyper-reflexia, extensor plantar response, and ankle clonus. This time the eyes showed a maintained conjugate deviation to the right.

When she was examined 3 days after this second episode the patient was alert and cooperative but was unable to turn her eyes voluntarily to the left of the primary position although they would turn at least part of the way with passive rotation of the head. The optokinetic response was absent on movement of the field to the patient's right but present and normal on rotation to the patient's left. Vertical gaze was normal and nystagmus was absent. The left extremities were paretic, with greater involvement of the arm than of the leg. The plantar reflex was extensor on the left. Pain and position sense were slightly reduced on the left. Arteriography showed an occlusion of the right internal carotid artery and a 50 per cent. narrowing of the left internal carotid artery at its bifurcation.

One week after onset, she could follow an object with her eyes to the left but was unable to turn them voluntarily; a week later she could turn her eyes about $30^{\circ}$ to the left on command.

She was discharged to a convalescent hospital where she is said to have had some continued limitation of gaze and spasticity of the left arm, but no further examination was made.

Ten months after the foregoing episode the patient developed chest pain and died of myocardial infarction. Autopsy revealed infarction of the right cerebrum and focal areas of infarction of the left cerebrum corresponding to the distribution of the internal carotid arteries.

Comment.-This patient had bilateral encephalomalacia resulting from occlusion of the internal carotid arteries. Symptomatic involvement of the right cerebral hemisphere followed 4 months after that of the left and was characterized by persistent deviation of the eyes to the right and paralysis of conjugate gaze to the left despite full recovery of consciousness.

Case 12, a 28-year-old woman, said to have become dizzy and fallen 2 days before admission to hospital. The details of this incident were obscure but she apparently struck the right frontotemporal region, developed an aching headache in this area, and vomited several times. The following day she continued to vomit, became increasingly confused, and was incontinent of urine. Over a period of a day or two she developed right-sided headache, left hemiplegia, and stiffness of the neck. She had had a "nervous breakdown" 6 years previously but this could not be documented further.

Neurological examination showed left hemiplegia with involvement of the face and palate, left-sided hypaesthesia, bilateral extensor plantar response and ankle clonus on both sides, marked restlessness, and moderate confusion. Lumbar puncture revealed a pressure of $290 \mathrm{~mm} . \mathrm{H}_{2} \mathrm{O}$ with 110,000 r.b.c. and 226 w.b.c. $/ \mathrm{mm}^{3}$. A right carotid arteriogram indicated increased density just lateral to the bifurcation of the right internal carotid artery; this was thought to be an aneurysm or a leak of contrast substance into a false aneurysm. Bilateral occipital and temporal burr holes showed no evidence of subdural haematoma. The presumptive diagnosis was ruptured aneurysm, but the reason for the bilaterality of the cerebral signs was unexplained.

With no further treatment the hemiplegia improved, although she continued to be extraordinarily restless and variable in her state of orientation. She was noted repeatedly to have a bilateral extensor plantar response and a repeat lumbar puncture showed a pressure of $90 \mathrm{~mm} . \mathrm{H}_{2} \mathrm{O}$ and xanthochromic spinal fluid.

Her eyes were first thoroughly tested 2 weeks after admission to hospital. She lay in bed with eyes, head, and body turned to the right. Her lids were kept closed most of the time except when she was specifically asked to open them or to fix an object. Through the closed lids the eyes could be seen to be stationary or directed straight ahead; they were not deviated to one side. The patient fixed an object on her right side so long as it was below the horizontal plane but she could not be made to look upwards. Fixation was maintained poorly, however, even for objects on the right side; instead, the eyes showed irregular oscillations of fixation over an arc of several degrees. When asked to fix an object on the left, she would turn her head and not move her eyes more than a 
few degrees past the straight ahead position. When asked why she did not turn her eyes instead of her head she volunteered that "the eyes pull and are tight" when she attempted to look to the left. Pursuit movements were no better than command movements. The optokinetic response was normal on rotation of the field to the left but absent on rotation to the right.

Convergence could not be elicited even when the patient read small print at a distance of $20 \mathrm{~cm}$. and she complained of diplopia for objects nearer than 0.5 metres.

The left pupil was consistently 1 to $2 \mathrm{~mm}$. larger than the right but both reacted readily to light. The visual acuity as measured with small print was approximately normal and the visual fields were full to confrontation.

During the next 2 weeks the patient was observed periodically. The eye movements became increasingly full to the left and eventually returned to normal. Convergence returned and the optokinetic response became symmetrical to each side.

Comment.-This patient had an obscure intracranial disease which manifested bilateral cerebral signs but with predominant involvement of the right frontoparietal area. For several weeks after the onset she had a persistent paresis of conjugate gaze to the left and paralysis of convergence.

\section{Discussion}

This is a small series of patients with neuro-ophthalmic symptoms believed to be due to bilateral cerebral lesions in areas other than the primary visual centres.

In the first group of patients the prominent symptoms were visual object agnosia and impairment of spatial perception. The patients were able to see objects and to recognize them by touch or by sound, but were unable to identify them visually. Faulty localization of objects in space was also a conspicuous and incapacitating symptom in two of the present patients as it had been in those reported by Holmes (1919). Kleist (1922) called this symptom "space blindness" and the misdirection and false grasping of objects "optical ataxia".

In all three patients of this group the visual agnosia was profound. Yet the patients were able to circumvent their visual inadequacy so effectively that a casual observer might have failed to recognize that anything was amiss. The patients may even have fooled themselves, for they were not disturbed by their inadequacy as much as one would have expected or as are patients with lesser degrees of aphasia.

The localization of lesions in the patients with agnosia is conjectural. In Case 1, in whom faulty stereopsis was especially prominent, the lesions were presumably biparietal; in Case 2, in whom object agnosia was outstanding, they were almost certainly bitemporal; in Case 3 , in whom object agnosia was also severe, they were presumably diffuse and involved some of the motor areas as well as the parietal area.

The supposition that global agnosia, as represented by the present patients, is a sign of bilateral disease, is supported by the observations of Holmes (1919) who reported eight patients with bilateral parietal injuries, and by Pool (1958) and Terzian (1958) who found little effect after unilateral temporal lobectomy but variously profound visual agnosia after bilateral temporal lobectomy. One amusing episode, illustrative of visual agnosia with bilateral lesions, is recorded by Pevzner, Bornstein, and Loewenthal (1962) in a patient with a lesion in the left parietum and right occiput: because the patient had lost the ability to recognize people by their faces (prosopagnosia) he got mixed up in court by talking to his opponent's lawyer when he thought he was talking to his own-with disastrous results! 
A condition comparable to visual agnosia has been produced in monkeys after experimental extirpation of both temporal lobes, the Klüver-Bucy syndrome (Klüver and Bucy, 1939; Mishkin and Pribram, 1954). The operated animals failed to recognize familiar objects by sight and, as a result, showed excessive mouthing or handling of common objects as though they were novel. Patients with visual agnosia show a similar compulsion to handle objects that they cannot recognize visually.

On the other hand numerous cases have been reported with less degrees of visual agnosia and topographic disorientation resulting from unilateral cerebral lesions (Riddoch, 1917; Kleist, 1922; Nielsen, 1937; Brain, 1941; McFie, Piercy, and Zangwill, 1950; Milner, 1958; Cogan, 1960). We, too, have seen severe spatial agnosia in a patient (not included in the series reported above) with signs pointing to one hemisphere only. This patient, who was thought to have multiple sclerosis, was a 26-year-old, strongly left-handed woman who developed left hemiparesis and inability to localize objects in space. She projected most objects, even those on her left side, into the right visual field and frequently looked at the wrong person while carrying on a conversation. Her ocular movements were slow and revealed a particular reluctance to look to the left or upwards. The only sign suggesting involvement of the contralateral (left) hemisphere in this patient was an inconstant extensor plantar response on the right side. Nevertheless, the possibility of bilateral disease in this case, as in most of the reported cases of severe visual agnosia with unilateral disease, cannot be unequivocally excluded.

In the controversy as to whether or not visual agnosias may result from unilateral lesions or indicate bilateral involvement, Brain (1941) has perhaps expressed the consensus by stating that the severe or global variety depends on lesions in both hemispheres but various minor forms may occur with unilateral lesions. This agrees best with our own observations.

The ocular motor abnormalities with bilateral cerebral disease have been less emphasized in the literature than have the agnosias. In Group IIa are five patients with what we have called "ocular motor apraxia" (Cogan and Adams, 1953) but which has been termed "spasm of fixation" by Holmes (1930), "locking of fixation" by Hecaen, Ajuriaguerra, Rouquès, David, and Dell, 1950), or "Balint's syndrome" in the general neurological literature (Balint, 1909). The most recent case reports and discussion in the literature are those of Saraux, Estève, Graveleau, and Goupil (1962). These patients are characteristically unable to turn their eyes purposively towards an object or to pursue a moving object with their eyes although they can turn their eyes at random. To the casual observer the patients appear blind, negativistic, or hysterical. Frequently the true nature of their ocular motor defect becomes apparent only in the stages of recovery when the control of movements returns to one side before the other.

Akinetic mutism was an associated symptom in four of these patients with ocular motor apraxia. The akinesia of eyes and speech showed the same deliberateness and superficial impression of negativism or hysteria. Furthermore, the disabilities improved concurrently, suggesting a common mechanism for both.

The five patients reported above do not establish the site of the lesion for ocular motor apraxia, but the evidence in two of them indicated biparietal localization, and in one bitemporal localization. Other workers have also reported biparietal 
localization (Smith and Holmes, 1916; Saraux and others, 1962), and have offered the interesting suggestion that the frontal areas must remain intact.

In patients of Group IIb the ocular motor defect consisted of prolonged palsy of the conjugate gaze. Unilateral cerebral lesions produce characteristically only transient deviation of the eyes and a palsy of conjugate gaze that persists no more than a few hours after the patient recovers consciousness. The temporary nature of the palsy serves to differentiate unilateral cerebral lesions from brain-stem lesions. The compensation for the cerebral lesion presumably occurs in corresponding portions of the opposite hemisphere. If this second hemisphere then develops a lesion the deviation persists for several weeks, long after recovery of consciousness. It can then be differentiated from the palsy of gaze that occurs with brain-stem lesions by the association of other symptoms pointing to the cerebral hemispheres and by the absence of brain-stem signs. Ocular motor apraxia, on the other hand, differs from the prolonged palsy of conjugate gaze in that there are difficulties only in initiating the movement with no limitations of the excursion.

These ocular motor abnormalities, both apractic and paralytic, eventually tend to recover, and are therefore usually seen with acute lesions only. They are not particularly incapacitating and for this reason have attracted little attention in the literature.

\section{Summary}

Twelve patients are described with neuro-ophthalmic symptoms resulting from bilateral cerebral lesions in areas other than the occipital lobes.

The symptoms and signs are categorized as follows:

Group I.-Those showing predominant disturbances in visual object recognition (visual agnosia) and disturbances of visual spatial localization.

Group IIa.-Those having defects in voluntary control of eye movements (ocular motor apraxia).

Group IIb.-Those with persistent palsies of conjugate gaze.

Although these symptoms may be present to some extent with unilateral lesions, they are much more profound and less able to be compensated with bilateral lesions.

The evidence in the present cases suggests a biparieto-temporal localization for the lesions causing visual agnosia, disturbances of spatial localization, and ocular motor apraxia, and a more frontal localization for the lesions causing prolonged paralysis of conjugate gaze.

\section{REFERENCES}

Balint, R. (1909). Mschr. Psychiat. Neurol., 25, 51.

BraIN, W. R. (1941). Brain, 64, 43.

Cogan, D. G. (1960). Amer. J. Ophthal., 50, 1056.

- and Adams, R. D. (1953). A.M.A. Arch. Ophthál., 50, 434.

$\longrightarrow$ (1955). Ibid., 53, 758.

Critchley, M. (1953). “The Parietal Lobes". Arnold, London.

DUKE-ELDER, W. S. (1949). "Text-book of Ophthalmology", vol. 4. Kimpton, London.

FAUST, C. (1947). Nervenarzt, 18, 103.

FreUd, S. (1891). " “Zur Auffassung der Aphasien; eine kritische Studie”. Deuticke, Leipzig.

Hecaen, H., Ajuriaguerra, J., de Rouquès, L., David, M., and Dell, M. B. (1950). Rev. neurol., 83, 81. 
Holmes, G. (1919). Brit. med. J., 2, 230.

(1930). Trans. ophthal. Soc. U.K., 50, 253.

KLEIST, K. (1922). " "Handbuch der ärztlicher Erfahrungen im Weltkrieg”, ed. von Schjerning, O., vol. 4, p. 343. Cited by Brain, W. R. (1941).

Klüver, H., and Bucy, P. C. (1939). Arch. Neurol. Psychiat. (Chicago), $42,979$.

MCFie, J., Piercy, M. F., and Zangwill, O. L. (1950). Brain, 73, 167.

Milner, B. (1958). In "The Brain and Human Behavior”. Res. Publ. Ass. Res. nerv. ment. Dis., $36,244$.

Mishinin, M., and Pribram, K. H. (1954). J. comp. physiol. Psychol., 47, 14.

Nielsen, J. M. (1937). Arch. Neurol. Psychiat. (Chicago), 38, 108. and Sanborn, A. L. (1942). Bull. Los Angeles neurol. Soc., 7, 102.

Pevzner, S., Bornstein, B., and Loewenthal, M. (1962). J. Neurol. Neurosurg. Psychiat., $25,336$.

Pool, J. L. (1958). In “Temporal Lobe Epilepsy”, ed. Baldwin, M., and Bailey, P., p. 558. Thomas, Springfield, Ill.

RidDOCH, G. (1917). Brain, 40, 15.

Saraux, H., Estève, P., Graveleau, D., and Goupil, H. (1962). Ann. Oculist. (Paris), $195,456$.

Smith, S., and Holmes, G. (1916). Brit. med. J., $1,437$.

Somerville-Large, L. B. (1960). Irish J. med. Sci., no. 411, 97.

Terzian, H. (1958). In "Temporal Lobe Epilepsy", ed. Baldwin, M., and Bailey, P., p. 510. Thomas, Springfield, Ill.

Walsh, F. B. (1957). “Clinical Neuro-ophthalmology”, 2nd ed. Williams and Wilkins, Baltimore. 